\title{
Factors of Students' Behavior Affecting Their Learning Achievement
}

\author{
*Dr. Shahida Naz ${ }^{1}$, Tahir Rasheed ${ }^{2}$, Memona Rasheed ${ }^{3}$ \\ 1. Assistant Professor, Department of Applied Linguistics Government College University Faisalabad, \\ 2. Department of English, National University of Modern Languages, (NUML) Multan, Pakistan \\ 3. Visiting Lecturer, Department of Economics, Government College University Faisalabad
}

\begin{abstract}
The present study examines the push and pulls factors of social behavior found in students studying at secondary school level and how they affect students' learning achievement. The data were collected from schools in four districts of Punjab province in Pakistan through random sampling technique. Exploratory Factor Analysis (EFA) was done to extracted six dimensions in two questionnaires designed for students and teachers. Five hundred students (252 females \& 248 males), and 120 teachers (60 males, 60 females) returned the questionnaires after filling properly. Exploratory Factor Analysis, Pearson Correlation, Paired sample t-test, SD and mean were calculated to measure the responses of students and teachers who participated in this study. The findings demonstrated that parents' conflicts, peer' bullying, teachers' insulting attitude and students' bad behaviour are the main push factors that are the major causes of de-motivating students and promote negative social behaviour among them. The students in these circumstances lost their interest in studies. They behave roughly and violate the institutions' rules \& regulations.
\end{abstract}

Keywords: Social Behaviour, Push Factors, Pull Factors, Learning factors, Learners' psychology 